Research Paper:

\title{
Assessment of Surgery, Complications, and Clinical Outcomes in Patients With Traumatic Spine
}

\author{
Sasan Andalib ${ }^{1,2,3}$, Zahra Mohtasham-Amiri ${ }^{1}$, Shahrokh Yousefzadeh-Chabok ${ }^{1,2,3^{*}}$, Alia Saberi ${ }^{2}$, Hamid Behzadnia ${ }^{3}$, Leila Kouchakine- \\ jad-Eramsadati ${ }^{1}$, Armaghan Sadeghi $^{1}$, Hadiseh Shokatjalil ${ }^{1}{ }^{Q}$, Sara Sayad-Fathi ${ }^{2}$ Q , Samaneh Ghorbani-Shirkouhi ${ }^{2}$ G
}

1. Guilan Road Trauma Research Center, Poursina Hospital, School of Medicine, Guilan University of Medical Sciences, Rasht, Iran

2. Neuroscience Research Center, Poursina Hospital, School of Medicine, Guilan University of Medical Sciences, Rasht, Iran

3. Department of Neurosurgery, School of Medicine, Guilan University of Medical Sciences, Rasht, Iran

\begin{tabular}{|c|c|}
\hline $\begin{array}{l}\text { Use your device to scan } \\
\text { and read the article online }\end{array}$ & CFtation:Andalib S Mohtasham-Amiri Z Yousefzadeh-Chabok Sh SaberiA Behzadnia H Kouchakineiad-Eramsadat L et al \\
\hline 口itiv & Assessment of Surgery, Complications, and Clinical Outcomes in Patients With Traumatic Spine. Iran J Neurosurg. 2019; 5(1): \\
\hline Hintist & 15-20. http://dx.doi.org/10.32598/irjns.5.1.15 \\
\hline 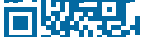 & d tef": http://dx.doi.org/10.32598/irjns.5.1.15 \\
\hline
\end{tabular}

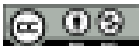

Article info:

Received: 15 Jun 2018

Accepted: 05 Nov 2018

Available Online: 01 Jan 2019

Keywords:

Spine trauma, Spinal cord injury, Surgery, Complications, Glasgow Outcome Scale

\begin{abstract}
Background and Aim: Spinal Cord Injury (SCI) is one of the main causes of severe disability and mortality following trauma. Complications and outcomes of patients with spine trauma, especially those who undergo surgery, are a less divulged topic in Iran. Therefore, we designed the present study to evaluate complications and outcomes of patients with traumatic spine in Poursina Hospital of Rasht.
\end{abstract}

Methods and Materials/Patients: In the present cross-sectional study, we referred to registry of spinal cord injuries of Poursina Hospital, which is a referral center for trauma in Rasht in the north of Iran. We investigated records of all the patients with traumatic spine confirmed by Computed Tomography (CT) scan or Magnetic Resonance Imaging (MRI) during 2016-2018. Demographic data, types of $\mathrm{SCl}$, types of surgical interventions, time from injury to surgery, number of fixed and fused vertebrae, complications, and outcome (based on Glasgow Outcome Scale (GOS) criteria) of the patients were evaluated upon discharge.

Results: In total, records of 274 patients with spine trauma were reviewed. The Mean \pm SD of age of the patients was $42.27 \pm 16.83$ years. There were 76 women $(27.7 \%)$ and 198 males $(72.3 \%)$. Surgical interventions were done for 148 patients (54\%). The median of time of surgical interventions for displacement of the vertebrae and the median of time for removal of pressure from spinal cord in the patients were 5 hours (range $=82$ hours). Median of duration of hospital stay was 2 days (range $=167$ days). $2.2 \%$ of the patients experienced complications. $85 \%$ of the patients showed good recovery according to GOS.

Conclusion: The evidence from the present study indicates that approximately half of the patients with spine trauma underwent operation. Good recovery was seen in roughly four fifth of all of the patients with spine trauma. Most of the patients had no complications during their stay in the hospital.

* Corresponding Author:

Shahrokh Yousefzadeh-Chabok, MD.

Address: Guilan Road Trauma Research Center, Poursina Hospital, School of Medicine, Guilan University of Medical Sciences, Rasht, Iran Tel: +98 (13) 33311472

E-mail: neurosurgery97@yahoo.com 


\section{Highlights}

- Approximately half of the patients with spine trauma admitted to Pousina Hospital of Guilan Province underwent operation.

- Good recovery was seen in roughly four fifth of all of the patients with spine trauma.

- Most of the patients had no complications during their stay at the hospital.

\section{Plain Language Summary}

Spinal Cord Injury is one of the main causes of severe disability and mortality following trauma. Complications and outcomes of patients with spine trauma, especially those who undergo surgery, are a less divulged topic in Iran. Therefore, we designed the present study to evaluate complications and outcomes of patients with traumatic spine in Poursina Hospital of Rasht. In the present study, we referred to registry of spinal cord injuries of Poursina Hospital, which is a referral center for trauma in Rasht in the north of Iran. We investigated records of all the patients with traumatic spine confirmed by CT scan or MRI during 2016-2018. In total, records of 274 patients with spine trauma were reviewed. The Mean of age of the patients was 42.27 years. There were 76 women (27.7\%) and 198 men (72.3\%). Surgical interventions were done for 148 patients (54\%). Median of duration of hospital stay was 2 days. In addition, $2.2 \%$ of the patients experienced complications, and $85 \%$ of the patients showed good recovery according to Glasgow Outcome Score. The evidence from the present study indicates that approximately half of the patients with spine trauma underwent operation. Good recovery was seen in roughly four fifth of all of the patients with spine trauma. Most of the patients had no complications during their stay in the hospital.

\section{Introduction}

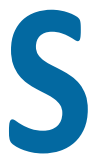

pinal Cord Injury $(\mathrm{SCl})$ is one of the main causes of severe disability and mortality following trauma. $\mathrm{SCl}$ mostly occurs in the young people leading to considerable costs [1]. More than 10,000 SCls occur annually in the United States [2]. Traumatic SCl is often due to road accidents, fall, and sport and may bring about $\mathrm{SCl}$ with complete and incomplete neurological deficits [3]. $\mathrm{SCl}$ may disrupt sensory or motor control of the trunk, lower and upper limbs, as well as autonomic control. These in turn can interfere functions of cardiovascular, respiratory, and sexual systems, temperature, stool and urine control. Statistics indicate that $\mathrm{SCl}$ mortality rate in males is approximately 3 times higher than that in women; even so, the severity of $\mathrm{SCl}$ in trauma is approximately 5 times higher than in none traumatic occasions [4]. Moreover, in the United States, men in all age groups experience higher rate of traumatic $\mathrm{SCl}$.

Average age of $\mathrm{SCl}$ is normally between 30 and 50 years, which indicates that $\mathrm{SCl}$ is associated with alcohol consumption, driving habits, and risky sports [4, 5]. Cervical $\mathrm{SCl}$ usually cause loss of sensation and movement in hands, trunk and legs, while thoracic $\mathrm{SCl}$ can result in loss of sensation or movement in trunk and legs [6].
Dislocation of vertebra and fractures are important concerns in spine trauma. Nonsurgical and surgical procedures are performed to treat spondylolisthesis and fractures caused by trauma, lessening the pressure on the spinal cord. Open anterior and posterior approaches are two general surgical approaches for spine surgery. Some patients will also undergo both approaches to increase access to the spine. Fixation and fusion of several vertebrae are important measures to treat their fractures [7].

Patients with spine trauma may experience complications including leakage of cerebrospinal fluid (CSF), bed sores, fever due to various types of infections (surgical wound infections, meningitis, pneumonia, septicemia and Urinary Tract Infection (UTI), to name but a few. Glasgow Outcome Scale (GOS) is used for assessment of clinical outcomes in patients with $\mathrm{SCl}$ [8]. Complications and outcomes of patients with spine trauma, especially those who undergo surgery, are a less divulged topic in Iran. Therefore, we designed the present study to evaluate complications and outcomes of the patients with spine trauma in Poursina hospital of Rasht. 


\section{Methods \& Materials/ Patients}

In the present cross-sectional study, we used registry of spinal cord injuries of Poursina Hospital, which a referral center for trauma in Rasht in the north of Iran. We investigated records of all the traumatic spine patients confirmed by CT scan or MRI during 2016-2018. Demographic data, types of spinal cord injury, types of surgical interventions, mean time from injury to surgery, number of fixed and fused vertebrae, complications, and outcomes of the patients upon discharge (based on GOS criteria) and other relevant information were extracted. Moreover, Type of complications included CSF leakage, bed sore, and fever.

\section{Results}

In this study, which was performed on records of 274 patients, the Mean \pm SD age of the patients was $42.27 \pm 16.83$ years. There were 76 women $(27.7 \%)$ and 198 males (72.3\%). Surgical interventions were done for 148 (54\%) of the patients, respectively. The median of time for surgical interventions leading to removal of the pressure from spinal cord were 5 hours (range $=82$ hours). Median of duration of hospital stay was 2 days (range $=167$ days). Type of intervention, number of fixed vertebrae, complications of hospitalization, type of complications, Intensive Care Unit (ICU) admission, and patient outcome according to GOS are summarized in the Table 1.

Of the 274 patients studied, $85 \%$ had a good recovery ( 233 cases) and $2.2 \%$ (6 cases) passed away. Of the 148 patients who underwent surgery, 123 cases (83.1\%) had a recovery outcome, 2 cases (1.4\%) had vegetative states and 1 case (0.7\%) passed away. 6 patients were discharged by their personal consent. Table 2 summarizes outcome of patients with traumatic spine in the whole group and in the operated group.

\section{Discussion}

Guilan as a touristic province in Iran has a different pattern of accidents. Spinal injuries are a major cause of death and in paralysis case, impose hefty costs on healthcare system. Epidemiologic awareness about these injuries helps healthcare systems to better plan for prevention, control, and management. The aim of the present study was to evaluate surgical measures,

Table 1. Type of intervention, number of fixed vertebrae, complications of hospitalization, type of complications, ICU admission, and patient outcome according to GOS

\begin{tabular}{|c|c|c|}
\hline \multicolumn{2}{|c|}{ Variable } & \multirow{2}{*}{$\begin{array}{c}\text { Frequency (\%) } \\
9(6.1)\end{array}$} \\
\hline & Anterior open surgery & \\
\hline \multirow[t]{2}{*}{ Type of intervention } & Posterior open surgery & $137(92.6)$ \\
\hline & Both & $2(1.3)$ \\
\hline \multirow{2}{*}{ Number of fixed vertebr } & Two vertebrae & $4(2.7)$ \\
\hline & Three vertebrae or more & $144(97.3)$ \\
\hline \multirow{2}{*}{ Complications of hospitalizati } & No & $268(97.8)$ \\
\hline & Yes & $6(2.2)$ \\
\hline \multirow{4}{*}{ Type of complications } & Bed sore & $2(33.3)$ \\
\hline & Fever & $2(33.3)$ \\
\hline & CSF leakage & $1(16.7)$ \\
\hline & Other & $1(16.7)$ \\
\hline \multirow{2}{*}{ ICU stay } & Yes & $224(81.8)$ \\
\hline & No & $50(18.2)$ \\
\hline
\end{tabular}


Table 2. Outcome of patients with traumatic spine in the whole group and in the operated group

\begin{tabular}{|c|c|c|}
\hline & & Frequency (\%) \\
\hline \multirow{5}{*}{ Patient outcome } & Good recovery & $233(85)$ \\
\hline & Moderate disability & $9(3.3)$ \\
\hline & Severe disability & $15(5.5)$ \\
\hline & Vegetative state & $4(1.5)$ \\
\hline & Death & $6(2.2)$ \\
\hline \multirow{5}{*}{$\begin{array}{l}\text { Patient outcome in } \\
\text { the operated group }\end{array}$} & Good recovery & $123(83.1)$ \\
\hline & Moderate disability & $7(4.7)$ \\
\hline & Severe disability & $15(10.1)$ \\
\hline & Vegetative state & $2(1.4)$ \\
\hline & Death & $1(0.7)$ \\
\hline
\end{tabular}

complications, and outcomes in patients with spine trauma in Guilan province of Iran.

We found that $72.3 \%$ (198 cases) of the patients were male and the average age of patients was 42.27 years. This was to some extent in agreement with findings of investigation of Rabiei et al. in Isfahan in Iran, in which the mean age of patients was 42 years and also two third of the patients was male $[9,10]$. In a study in Kashan in Iran, Fakharian et al. the mean age of patients was 39 (range $20-50$ years old), and $78 \%$ of the patients were male [11]. Rabiei et al. reported that $18 \%$ of their patients with spine fracture were operated due to spinal fractures [10]. Among the patients, $18.2 \%$ stayed in ICU. Finally, an assessment of outcomes according to GOS showed that $85 \%$ of the cases had a good recovery. Moderate and severe disability was seen in $3.3 \%$ and $5.5 \%$ of the patients respectively, notwithstanding $2.2 \%$ of the patients passing away. De Giacomo et al. reviewed 142 patients operated by an anterior approach of thoracic vertebrae of which 20 patients had traumatic spine [12].

The author reported a mean of $\mathbf{3 7 0}$ minutes for duration of the surgeries. We found that the median of time for surgical interventions for displacement of the vertebrae and the median time for removal of the pressure from spinal cord in the patients were 5 hours. Baram et al. operated 15 patients with dislocation of fractured vertebrae by using an anterior approach and did fixation and fusion with screw and autograft [9]. The authors re- ported complications including infection $(n=4)$, hemothorax $(n=2)$, screw loosening $(n=1)$, Horner syndrome $(n=1)$, hematoma $(n=1)$, urinary tract infection $(n=1)$, Deep Vein Thrombosis (DVT) and pulmonary embolism $(n=1)$. In our patients, we observed bed sore, fever, and CSF leakage, in 2, 2, and 1 patient, respectively. Xu et al. operated 21 patients with spine trauma and stenosis [13]. Fixation for 2 vertebrae with 4 screws in 7 patients, 3 vertebrae with 6 screws in 10 patients, 4 vertebrae with 8 screws in 4 patients. Mean of surgery time was 190 minutes. CSF leakage, and delayed surgical wound recovery were seen in 4 patients. Respiratory infection was seen in 3 patients of which one had also urinary infection. One of the patients died due to respiratory failure.

Fredo et al. operated 303 patients with subaxial cervical spine fractures treated with open surgical fixation [14]. 155 patients underwent anterior cervical decompression and fusion with anterior plating. 54 patients underwent corpectomy with autologous iliac crest graft and anterior plating. 42 patients underwent Posterior fusion with wiring technique. 24 patients underwent posterior fusion with lateral mass screws. 22 patients experienced complications including CSF leakage, infection, hematoma, suboptimal placement of screws, fixation failure, vertebrae balance failure.

6 patients were discharged by their personal consent. It can be concluded that trauma and spinal fracture surgeries can be highly successful in improving physical 
performance and patient quality of life and in this regard, the incidence or mortality of patients is very low. In developed countries, mortality due to spine trauma ranges between $3.1 \%$ and $22.2 \%$ [15, 16]. However, in underdeveloped countries, it has been demonstrated to be $1.4 \%$ [17]. Elsewhere, in Botswana, this rate increased to $20 \%$ [18]. Therefore, considering the severity of traumatic injuries, the results of the present study seem to be quite desirable. It is worth noting that patients with trauma and spinal cord injury may also be seriously injured in the other organs or other parts of their bodies; therefore, the diagnosis and intervention of these patients require a proper decision.

\section{Conclusion}

The evidence from the present study indicates that approximately half of the patients with spine trauma admitted to Pousina Hospital of Guilan Province underwent operation. Good recovery was seen in roughly four fifth of all of the patients with spine trauma. Most of the patients had no complications during their stay at the hospital. Further study with a bigger sample size is suggested.

\section{Ethical Considerations}

\section{Compliance with ethical guidelines}

The study was approved by institutional ethics committee (Code: IR.GUMS.REC.1397.519).

\section{Funding}

This research did not receive any specific grant from funding agencies in the public, commercial, or not-forprofit sectors.

\section{Authors contributions}

Sasan Andalib and Zahra Mohtasham Amiri (co-first authors) contributed equally to the paper. All authors met ICMJE criteria.

\section{Conflict of interest}

The authors declare no conflict of interest with respect to the present paper.

\section{Acknowledgements}

We thank Guilan Road Trauma Research Center for its support.

\section{References}

[1] Emamhadi MR, Soltani B, Yousefzadeh-Chabok Sh, Babaee P, Behzadnia H, Ghadarjani Sh, et al. Evaluation of mesenchymal stem cells and granulocyte colony stimulating factor in treatment of complete spinal cord injury. Journal of Experimental \& Clinical NeuroSciences. 2018; 5(1):1-5.

[2] White NH, Black NH. National spinal cord injury statistical center, facts and figures at a glance. Birmingham, AL: University of Alabama at Birmingham; 2016.

[3] Andalib S, Mohtasham-Amiri Z, Yousefzadeh-Chabok Sh, Saberi A, Reihanian Z, Kouchakinejad-Eramsadat L, et al. Epidemiology of spine trauma and spinal cord injuries in the north of Iran. Iranian Journal of Neurosurgery. 2018; 4(4):199204. [DOI:10.32598/irins.4.4.180]

[4] Stark S. Creating disability in the home: The role of environmental barriers in the United States. Disability \& Society. 2001; 16(1):37-49. [DOI:10.1080/713662037]

[5] Wee J, Paterson M. Exploring how factors impact the activities and participation of persons with disability: Constructing a model through grounded theory. The Qualitative Report. 2009; 14(1):165-200.

[6] Andalib S, Mohtasham-Amiri Z, Yousefzadeh-Chabok Sh, Saberi A, Emamhadi MR, Kouchakinejad-Eramsadati L, et al. Traumatic spinal cord injuries due to motor vehicle accidents. Iranian Journal of Neurosurgery. 2018; 4(4):213-8. [DOI:10.32598/irjns.4.4.195]

[7] Fehlings MG, Vaccaro A, Wilson JR, Singh A, Cadotte DW, Harrop JS, et al. Early versus delayed decompression for traumatic cervical spinal cord injury: Results of the Surgical Timing in Acute Spinal Cord Injury Study (STASCIS). PloS One. 2012; 7(2):e32037. [DOI:10.1371/journal.pone.0032037] [PMID] [PMCID]

[8] McMillan T, Wilson L, Ponsford J, Levin H, Teasdale G, Bond M. The Glasgow Outcome Scale - 40 years of application and refinement. Nature Reviews Neurology. 2016; 12:477-85. [DOI:10.1038/nrneurol.2016.89] [PMID]

[9] Baram A, Al-Tameemi AAA, Shali WF. Anterior approach for thoracolumbar fracture dislocations: Surgical management in poor resource region, record of 7 years follow-up. Journal of Spine. 2016; 5(5):1000331. [DOI:10.4172/21657939.1000331]

[10] Rabiei A, Tabesh H. [Epidemiological study of vertebral trauma in Isfahan Province during 2012-2018 (Persian)]. Feyz, Journal of Kashan University of Medical Sciences. 2019; 23(1):102-7.

[11] Fakharian E, Tabesh H, Masoud SA. [An epidemiologic study on spinal injuries in Kashan (Persian)]. Journal of Guilan University of Medical Sciences. 2004; 13(49):79-85.

[12] De Giacomo T, Francioni F, Diso D, Tarantino R, Anile M, Venuta F, et al. Anterior approach to the thoracic spine. Interactive Cardiovascular and Thoracic Surgery. 2011; 12(5):6925. [DOI:10.1510/icvts.2010.257360] [PMID]

[13] Xu ZW, Lun DX. Surgical management of multilevel cervical spinal stenosis and spinal cord injury complicated by cervical spine fracture. Journal of Orthopaedic Surgery and Research. 2014; 9:77. [DOI:10.1186/s13018-014-0077-4] [PMID] [PMCID] 
[14] Fredø HL, Rizvi SAM, Rezai M, Rønning P, Lied B, Helseth E. Complications and long-term outcomes after open surgery for traumatic subaxial cervical spine fractures: A consecutive series of 303 patients. BMC Surgery. 2016; 16:56. [DOI:10.1186/s12893-016-0172-z] [PMID] [PMCID]

[15] Dryden DM, Saunders LD, Jacobs P, Schopflocher DP, Rowe BH, May LA, et al. Direct health care costs after traumatic spinal cord injury. Journal of Trauma and Acute Care Surgery. 2005; 59(2):441-7. [DOI:10.1097/01.ta.0000174732.90517. df] [PMID]

[16] Lenehan B, Street J, Kwon BK, Noonan V, Zhang H, Fisher CG, et al. The epidemiology of traumatic spinal cord injury in British Columbia, Canada. Spine. 2012; 37(4):321-9. [DOI:10.1097/BRS.0b013e31822e5ff8] [PMID]

[17] Ning GZ, Yu TQ, Feng SQ, Zhou XH, Ban DX, Liu Y, et al. Epidemiology of traumatic spinal cord injury in Tianjin, China. Spinal Cord. 2011; 49(3):386-90. [DOI:10.1038/sc.2010.130] [PMID]

[18] Lofvenmark I, Norrbrink C, Nilsson-Wikmar L, Hultling C, Chakandinakira S, Hasselberg M. Traumatic spinal cord injury in Botswana: Characteristics, aetiology and mortality. Spinal Cord. 2015; 53(2):150-4. [DOI:10.1038/sc.2014.203] [PMID] 